\title{
BARAKAT SYNDROME: AN UNCOMMON CAUSE OF HYPOCALCEMIA
}

\author{
Teresa Rego, Fernando Fonseca, Ana Agapito \\ Endocrinology Department, Curry Cabral Hospital, C.H.L.C., Lisbon, Portugal
}

\section{INTRODUCTION}

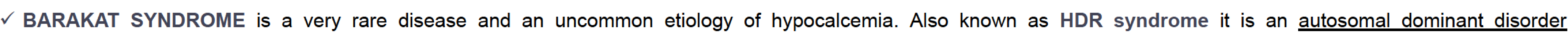
characterized by hypoparathyroidism, sensorineural deafness and renal disease.

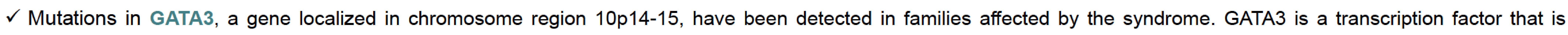
involved in the embryonic development of parathyroid glands, kidneys, inner ears, thymus and central nervous findings.

\section{CLINICAL CASE}

\section{$1990-35$ years old}

- Admitted in Emergency department with generalized seizures and signs and symptoms of cardiac failure.

- Intracranial basal ganglia calcifications were revealed at this time and a diagnosis of HYPOCALCEMIC miocardiopathy was established.

- Started calcium replacement.

\section{$\underline{\text { January } 2014}$}

- Hospitalized due to hypocalcemia $(6.9 \mathrm{mg} / \mathrm{dL})$ and acute heart failure.

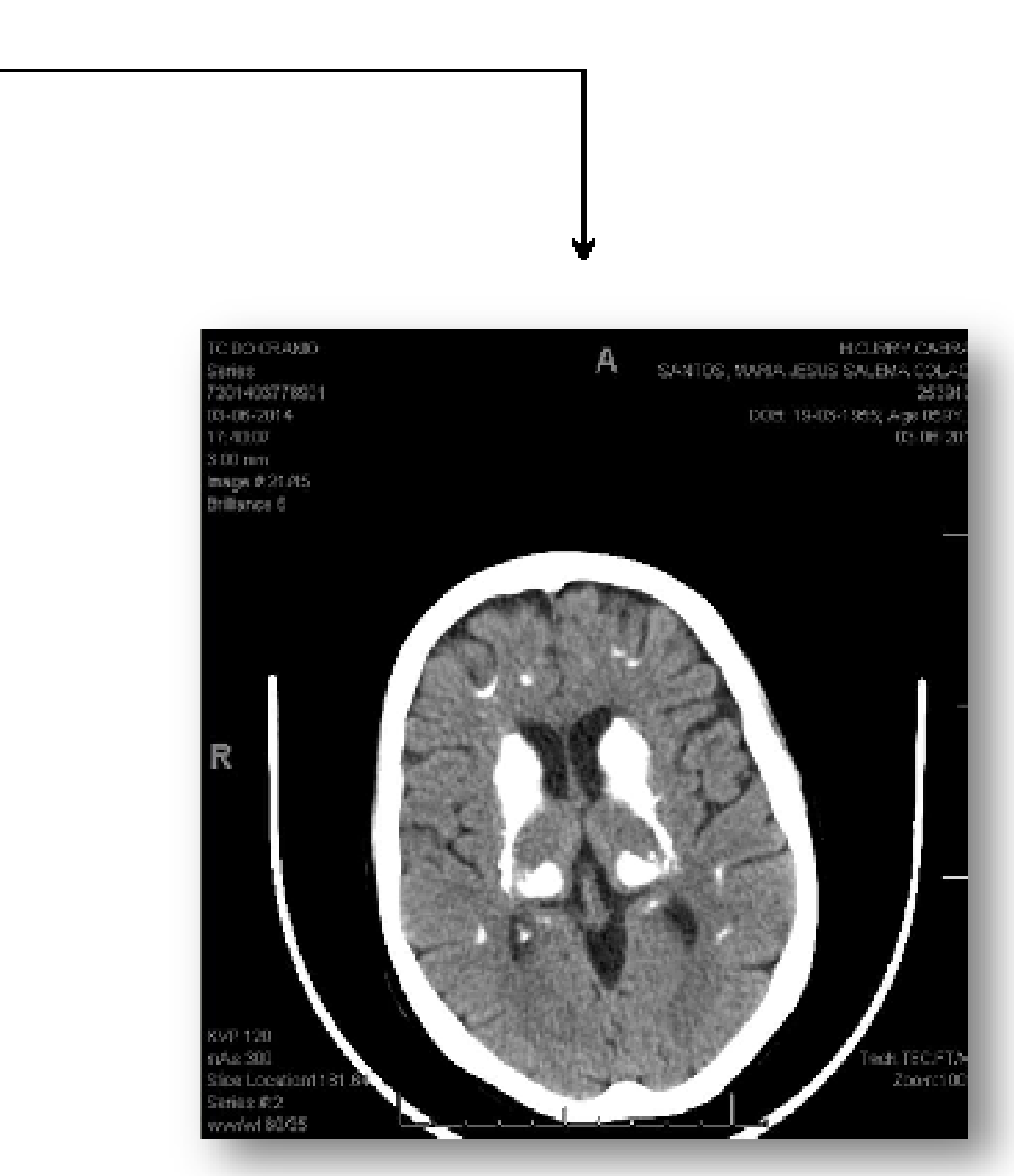

Progressive HEARING LOSS over the last 20 years / Diagnosed with BILATERAL NEUROSENSORY DEAFNESS

\section{May $2014-59$ years old}

- Admitted in the Endocrinology ward due to hypocalcemia despite being medicated with oral calcium ( $1 \mathrm{~g} /$ day of calcium carbonate and calcitriol $0.75 \mathrm{ug} /$ day)

- She complained of tiredness, decreased muscle strength and unsteadiness when walking, for the last twelve months.

HOSPITALIZED
Initiated calcium carbonate $3 \mathrm{~g} /$ day +
calcitriol $0.75 \mathrm{ug} / \mathrm{dia}$

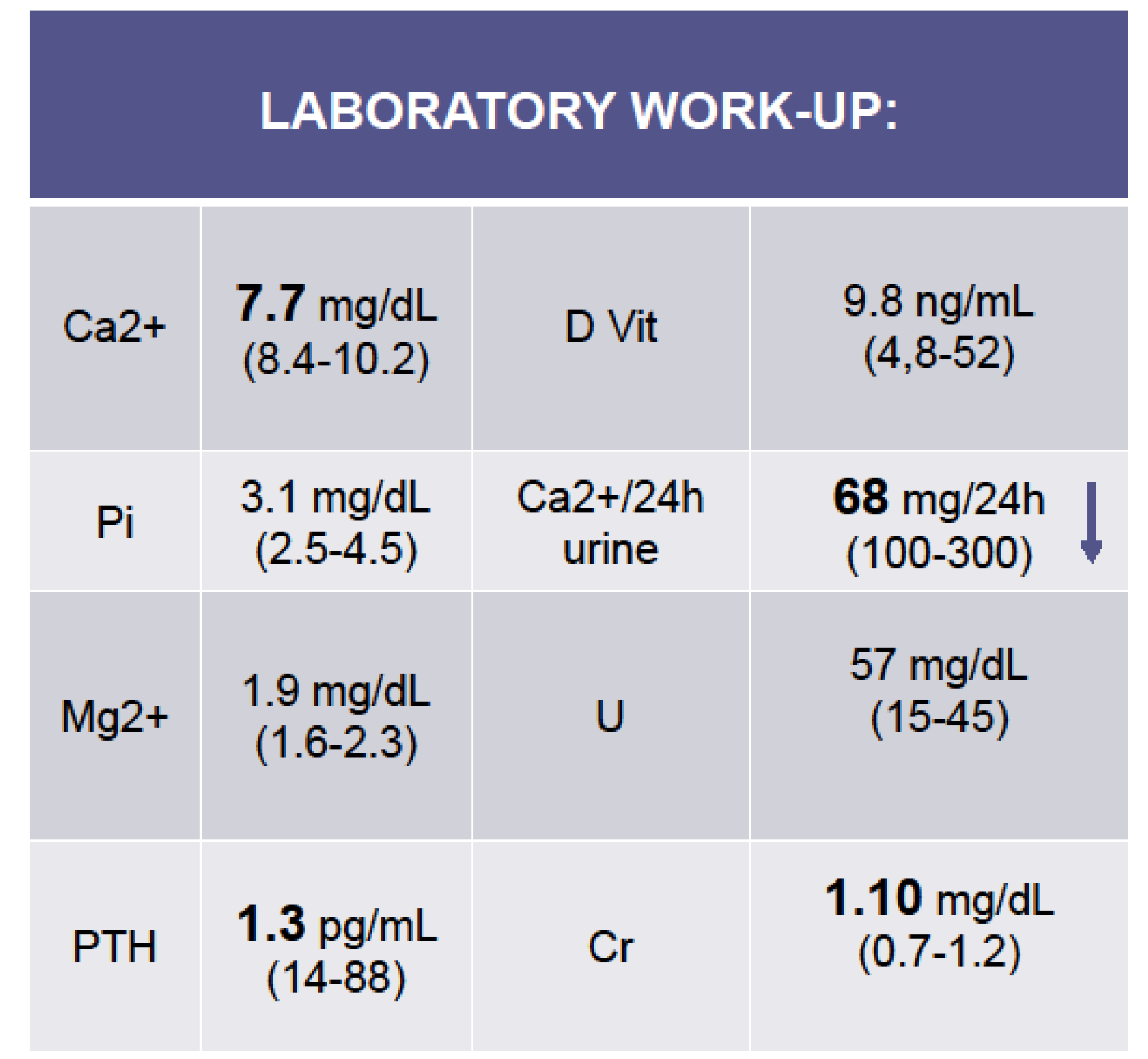

ABDOMINAL CT SCAN

Right kidney hypoplasia
HYPOPARATHYROIDISM NEUROSENSORIAL DEAFNESS
RENAL DISEASE
BARAKAT / HDR SYNDROME SUSPECTED

DNA sequence analysis revealed on exon 5 of GATA 3 gene a heterozygotic mutation c.1043T>C (p.Leu348Pro), that CONFIRMED the diagnosis of BARAKAT SYNDROME.

\section{FAMILY HISTORY}

We observed one of the two adult sons and the adult daughter of this patient:

38 years old, paraplegic due to a work accident. Bilateral deafness since infancy.

- Ca2+ 7.4 mg/dL (8.4-10.2); PTH 11 pg/mL (11-80). Renal ecography: Normal.

21 years old, bilateral deafness diagnosed at 15 years old.

$\mathrm{Ca} 2+8.6 \mathrm{mg} / \mathrm{dL}(8.8-10.8) ; \mathrm{PTH} 19 \mathrm{pg} / \mathrm{mL}(12-88)$

The same mutation was identified in her children - c.1043T>C(p.Leu348Pro) on exon 5 of GATA3

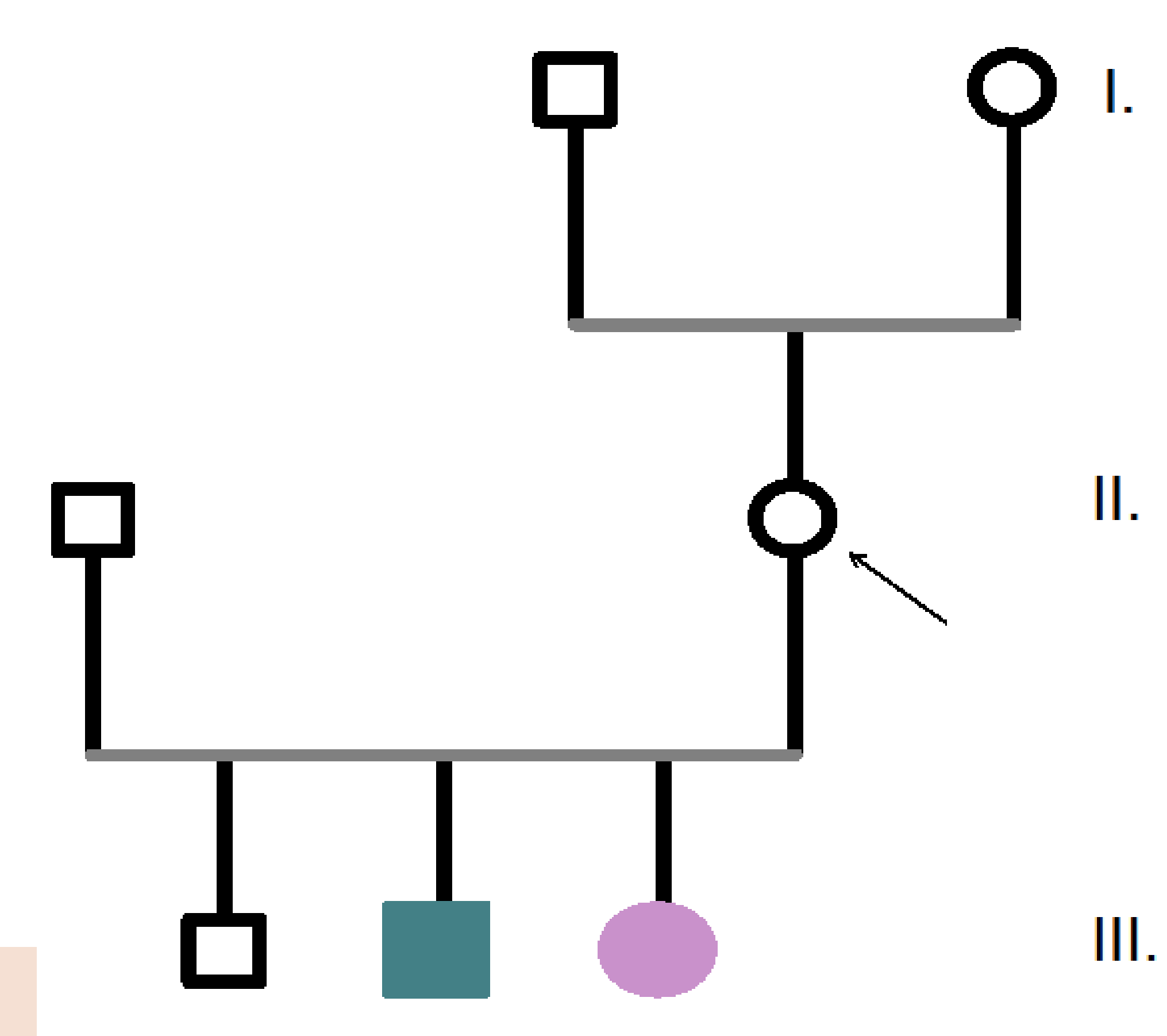

III.

\section{COMMENTS}

$\checkmark$ Barakat syndrome may present a variable phenotype. Renal manifestations are the most heterogeneous and usually determine disease prognosis.

$\checkmark$ This patient has the classical triad. The severity of hypocalcemia since young age and subsequent irreversible cardiac involvement were determinant for prognosis.

$\checkmark$ Timely diagnosis and appropriate hypocalcemia treatment are paramount. Genetic screening of relatives takes particular relevance in this context.

\section{BIBLIOGRAPHY}

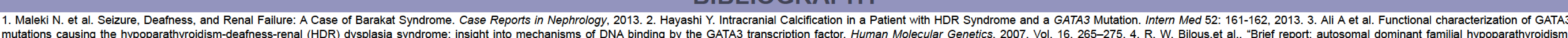

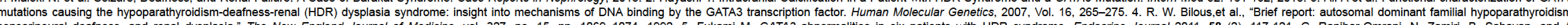
sensorineural deafness, and renal dysplasia," The New England Journal of Medicine, vol. 327, no. 15, pp. 1069-1074, 1992. 5. Fukami M. GATA3 abnormalities in six patients with HDR
Mohammadzadeh, "Concomitant hypoparathyroidism, sensorineural deafness, and renal agenesis: a case of Barakat syndrome," Archives of Iranian Medicine, vol. 11, no. 3, pp. 337-340, 2008. 